\title{
Determination of the Amounts Available for Long-Term Investment in an Insurance Company
}

\author{
by Eugenio Prieto Perez*
}

Insurance companies receive premiums in order to settle claims which may become payable in the future. This means that the companies will accumulate funds which can be invested on long terms. As the claims are of a random nature, the funds available for such investments must be represented by a stochastic variable, so the portfolio model of Markowitz [2] may not be immediately applicable. To analyse the situation it is convenient to consider the following two problems separately :

Problem 1 : To determine the amount which can be invested on long terms, given the risk situation of the insurance company.

Problem 2: To decide how the money should be invested, i.e. to find the optimal portfolio which should be acquired for the funds available for long term investment.

In the present paper we shall give a solution to the first of these problems. The second problem was discussed by the author in a paper presented to the international congress of actuaries in Tokyo in 1976 [3].

\section{A first model}

Let the stochastic variable $X$ represent claims in a portfolio of insurance contracts in given period $(0, t)$, and let the distribution function be $F(x)=\operatorname{Pr}(X \leqslant x)$. Let further $S$ be the funds which at the beginning of the period are available to the insurance company holding the portfolio. The company's situation is then described by the pair $(S, F(x))$.

Let $K \in(0,1)$ be the pant of the funds which is kept as a liquid reserve. The remainder, i.e. the amount $S(1-K)$ is then considered as available for long-term investments. If we take $t=1$, the funds of the company at the end of the period will be

$$
S\{K+(1-K)(1+i)\}-X
$$

Here $i$ is the yield of the investment.

If $X>K S$, the company will not be able to pay the claims out of its liquid reserves. The probability of this event is

$$
\operatorname{Pr}(X>K S)=1-F(K S)
$$

* Professor of Finance and Actuarial Science at the Independent University of Madrid. 
If the company has to liquidate some of its long-term investments, it will incur a cost of $c$ per unit. The expected value of these costs will be

$$
c \int_{K S}^{\infty}(x-K S) d F(x)
$$

Let us now assume that the company's attitude to risk can be represented by the utility function $u(x)$, and consider the expression

$$
\begin{aligned}
\Phi(K) & =\int_{0}^{K S} u\{K S+(1-K)(1+i) S-x\} d F(x) \\
& +\int_{K S}^{\infty} u\{K S+(1-K)(1+i) S-x-c(x-K S)\} d F(x)
\end{aligned}
$$

The problem of the company is with this formulation to determine the value of $K$, say $K^{*}$, which maximizes the expected utility (1).

Special case. Let us take $u(x)=x$, so that (1) reduces to

where

$$
\Phi(K)=S+(1-K) i S-m-c \int_{K S}^{\infty}(x-K S) d F
$$

$$
m=\int_{0}^{\infty} x d F(x)
$$

The first order condition for a maximum is

or

$$
\Phi^{\prime}(K)=-i S+c S[1-F(K S)]=0
$$

The second order condition

$$
F(K S)=1-\frac{i}{c}
$$

$$
\Phi^{\prime \prime}(K)=-c S^{2} F^{\prime}(K S)<0
$$

is satisfied whenever a density exists.

Numerical example. Let us assume that $F(x)$ is normal, with expectation $m=800$ millions, and standard deviation $s=100$ millions. Let us further assume that the interest rate is $i=0.08$, that the cost of liquidation is $c=0.1$ and that the funds of the company amount to Pesetas 1500 millions. We then have

or

$$
F(K S)=\frac{1}{100 \sqrt{2 \pi}} \int_{0}^{K S} e^{-\frac{1}{2}\left(\frac{x-800}{100}\right) 2} d x=1-\frac{8}{10}=0.2
$$

$$
\frac{1}{\sqrt{2 \pi}} \int_{-\infty}^{15 K-8} e^{-\frac{1}{2} x^{2}} d x=0.2
$$

From this we find $K=0.476$, so that the company can invest 52.4 per cent of its funds, or Pesetas 786 millions on long terms. 
Critical examination of the model. The model is very simple, but it brings out some of the essential elements in the decision problem. The model shows i.a. that the optimal investment decision depends on :

(i) The return on the portfolio of assets.

(ii) The cost of forced liquidation of assets in order to pay claims.

(iii) The shape of the claim distribution function $F(x)$.

The claim distribution can be modified by reinsurance, and Borch $[1$, p. 22] observes: "This means that the investment and reinsurance decisions should be analysed together, and that the ultimate aim should be to find decisions which are jointly optimal". This may seem a trivial observation, but there has been a tendency, both in theory and practice, to treat the two decisions separately. Actuaries usually seek reinsurance arrangements which will reduce the fluctuations in claim payments and bring the probability of ruin down to an acceptable level. Only exceptionally will they try to coordinate this work with the activity of the invesment department of the company. This department is likely to base its work on some variety of portfolio theory which assumes that the amount available for investment is known with certainty. This means that the cost of forced liquidation of assets is ignored.

\section{A second model, with reinsurance}

In general a reinsurance contract is a transformation $T(X)=Y$, which changes the stochastic variable $X$ into $Y$.

The simplest arrangement is the "proportional" or "quota share contract" given by

$$
T(X)=a X \quad a E(0,1)
$$

Under this contract the ceding company will pay only $\alpha x$ if claims in the original portfolio amount to $x$. The balance $(1-\alpha) x$ is paid by the reinsurer.

Another form of reinsurance is the "stop loss contract" described by the transformation

$$
\begin{aligned}
& T(X)=X \quad \text { for } \quad 0 \leqslant X \leqslant M \\
& T(X)=M \quad \text { for } \quad M<X
\end{aligned}
$$

Under this contract the ceding company will pay all claims itself, as long as the total does not exceed $\boldsymbol{M}$. All excesses will be paid by the reinsurer.

The quota share contract. Let $U$ be the company's initial capital, and $P$ be the premium it receives by underwriting a portfolio with claim distribution $F(x)$. Under the reinsurance contract, the company retains only a quata $\alpha$ of the premium, and pays only a fraction $\alpha$ of the claims.

The company's funds at the end of the contract period will be

$$
(U+\alpha P)\{K+(1-K)(1+i)\}-\alpha X
$$

We see that if

$$
X>\frac{K(U+\alpha P)}{\alpha}=K Z
$$


the company will have to liquidate assets in order to pay claims. As in the first model we find that the company's expected utility is given by the expression

$$
\begin{aligned}
\Phi(K, \alpha) & =\int_{0}^{K Z} u(\alpha\{K Z+(1-K)(1+i) Z-X\}) d F(x) \\
& +\int_{K Z}^{\infty} u(\alpha\{K Z-(1-K)(1+i) Z-X-c(X-K Z)\}) d F(x)
\end{aligned}
$$

The problem is now to determine the values of $K$ and $\alpha$ which maximize this expression.

The expressions (1) and (2) are practically identical, and it is easy to construct examples which can be solved explicitly. Some complications will however occur because in the second model $Z$ depends on the decision variable $\alpha$.

The stop loss contract. This contract is defined by the limit $M$, and the premium $Q$ which the reinsurer demands. If we ignore loadings and take $Q$ as net premium, we have :

$$
Q=\int_{M}^{\infty}(X-M) d F(X)
$$

The funds held by the company at the end of the contract period will be :

$$
\begin{array}{ll}
(U+P-Q)\{K+(1-K)(1+i)\}-X & \text { for } X \leqslant M \\
(U+P-Q)\{K+(1-K)(1+i)\}-M & \text { for } M<X
\end{array}
$$

We shall write $U+P-Q=Z$, and assume that

$$
K Z<M
$$

We then find the following expression for the expected utility :

$$
\begin{aligned}
\Phi(K, M) & =\int_{0}^{K Z} u(Z\{K+(1-K)(1+i)\}-X) d F(X) \\
& +\int_{K Z}^{M} u(Z\{K+(1-K)(1+i)\}-X-c(X-K Z)) d F(X) \\
& +u(Z\{K+(1-K)(1+i)\}-M-c(M-K Z))(1-F(M))
\end{aligned}
$$

The problem is now to maximize (4), subject to (3) - or to some other formula for computing the stop loss premium.

\section{Generalizations}

The models we have considered can be generalized in several directions. One possibility would be to assume that there are several investments, with different degrees of liquidity. We would then have to replace the scalar $c$ by a vector $\left\{C_{1}, C_{2}, \ldots, C_{n}\right\}$. If claims should exceed the company's liquid reserves, the company would have to sell some assets, and it would naturally sell those with the lowest liquidation costs. 
We could also take the whole step to a fully dynamic model. We would then be led to consider two sets of stochastic processes:

The payment process $\left\{X_{t}\right\}$ with components $X_{t}^{(1)}, X_{t}^{(2)}, \ldots$, representing claim payments, administrative expenses, liquidation costs, expenditure for sales promotion, etc.

The income process $\left\{I_{t}\right\}$ with components $I_{t}(1), I_{t}{ }^{(2)}, \ldots$, representing premium income, return from different types of investment, etc. process

The funds of the company at time $t$ would then be represented by a stochastic

$$
Z_{t}=\sum_{i} I_{t}^{(i)}-\sum_{j} X_{t}^{(j)}
$$

Each component might be influenced by some control variables, and by appropriate choice of these variables, management should be able to steer the $Z$-process so that it develops in an optimal manner. The study of such models may lead to a more general theory for the management of insurance companies.

We are at present working in this direction, and hope that we shall be able to report on additional results on another occasion.

\section{REFERENCES}

1. BORCH, K.: "The optimal portfolio of assets in an insurance company", Transactions of the I8th International Congress of Actuaries, Munich 1968, 21-31.

2. MARKOWITZ, H. M.: Portfolio Selection : Efficient Diversification of Investments, John Wiley \& Sons, New York, 1959.

3. PRIETO PEREZ, E. : "The insurance entities as financial intermediaries", Transactions of the 20th International Congress of Actuaries, Tokyo 1976, 687-694. 